\title{
Unsuspected femoral hernia in patients with a preoperative diagnosis of a recurrent inguinal hernia, author reply
}

\author{
N. A. Henriksen $\cdot$ J. Thorup $\cdot$ L. N. Jorgensen
}

Received: 8 June 2012/Accepted: 9 August 2012/Published online: 1 September 2012

(C) Springer-Verlag 2012

We would like to thank Dr. R. Bendavid for the thorough comment on our paper 'Unsuspected femoral hernia in patients with a preoperative diagnosis of recurrent inguinal hernia'. However, we are afraid that Dr. R. Bendavid may have missed the aim of the study from which we quote: 'The aim of this study was to examine the incidence of unsuspected femoral hernia discovered at transabdominal preperitoneal (TAPP) laparoscopic inguinal hernia repair in two well-defined groups: (1) patients with bilateral primary inguinal hernia and (2) patients with recurrent inguinal hernia'. When the aim is to examine unsuspected femoral hernias, it would be paradoxical to include patients with a preoperative diagnosis of a femoral hernia. Dr. R. Bendavid prefers to mention his series of 508 open femoral hernia repairs $[1,2]$, which is of course noteworthy; however, it does not cover unsuspected femoral hernias and is therefore not within the subject of our article.

Dr. R. Bendavid claims that the article is in favour of laparoscopic hernia surgery. In fact, the majority of inguinal hernia repairs are performed by open approach in our department. Firstly, referring to the aim of the study again, we examined unsuspected femoral hernias in patients undergoing laparoscopic hernia repair. Secondly, we do believe that laparoscopic approach is preferable in selected cases such as bilateral primary inguinal hernias, recurrent inguinal hernias after Lichtenstein repair and groin hernias in women. This selection is based on the guidelines of the European Hernia Society (EHS) [3] and not on our own personal experience. However, we noted that Dr. R. Bendavid does not agree with the EHS guidelines on several points including the definition of a femoral hernia.

Furthermore, we have been misunderstood by Dr. R. Bendavid and must clarify that we do not operate on patients with asymptomatic inguinal hernias. Finally, Dr. R. Bendavid has cited us incorrectly. We have stated in our paper that we do not find the Lichtenstein repair to be herniogenic.

\section{References}

1. Bendavid R (1989) Femoral hernias: primary versus recurrence. Int Surg 74:99-100

2. Bendavid R (2006) Inguinal herniorrhaphy in women. Hernia 10:103-104

3. Simons MP, Aufenacker T, Bay-Nielsen M, Bouillot JL, Campanelli G, Conze J et al (2009) European Hernia Society guidelines on the treatment of inguinal hernia in adult patients. Hernia 13:343-403 